\title{
Durability of the reaction to fire performance for fire retardant treated (FRT) wood products in exterior applications - a ten years report
}

\author{
Birgit Östman and Lazaros Tsantaridis
}

SP Wood Building Technology Stockholm, Sweden

\begin{abstract}
Several long term experimental studies on the maintained reaction to fire performance of fire retardant treated (FRT) wood products over time are presented. They are performed according to a European system based on earlier Nordic and North American systems and include accelerated ageing according to different procedures and natural weathering up to ten years. Main conclusions are:

- The hygroscopic properties are unchanged compared to untreated wood for most FRT wood products used commercially.

- The reaction to fire properties of FRT wood may be maintained after accelerated and natural ageing if the retention levels are high enough, but several FRT wood products loose most of their improved reaction to fire properties during weathering.

- Paint systems contribute considerably to maintain of the fire performance at exterior application and are usually needed to maintain the fire performance after weathering.
\end{abstract}

\section{INTRODUCTION}

\subsection{Durability classes for fire performance - Principles and methods}

Fire retardants may considerably improve the reaction to fire properties of wood products, but the durability in interior and exterior applications needs to be addressed. Requirements on durability of the fire performance are not mentioned in most building codes. This is probably partly caused by unawareness of the problem, but may also be due to the lack of procedures.

The problems with maintained reaction to fire performance over time have been known for a long time in the US and the UK, but are not so well known in the rest of Europe. A US study on exterior exposure of North American products during ten years [1] and a literature review [2] have been published.

Two cases of durability of the fire retardant treatment of wood products can be identified. One is the risk for high moisture content and migration of the fire retardant chemicals within the wood product and salt crystallisation on the product surface. These hygroscopic properties of the treated wood-based product can be evaluated by exposure to high relative humidity. 
Table 1. Requirements for DRF classes of FRT wood products according to CEN/TS 15912 [3].

\begin{tabular}{|c|c|c|c|c|}
\hline \multirow[t]{2}{*}{ DRF class } & \multirow[t]{2}{*}{ Intended use } & \multirow{2}{*}{$\begin{array}{l}\text { Fire class } \\
\text { Initial }\end{array}$} & \multicolumn{2}{|c|}{ Performance requirements for different end uses } \\
\hline & & & Hygroscopic properties & $\begin{array}{l}\text { Fire performance after } \\
\text { weather exposure }\end{array}$ \\
\hline ST & Short term & $\begin{array}{l}\text { Relevant fire } \\
\text { class }\end{array}$ & - & - \\
\hline & $\begin{array}{l}\text { Interior, dry } \\
\text { applications }\end{array}$ & $-"-$ & $\begin{array}{l}\text { Limited moisture content } \\
\text { Minimum visible salt }\end{array}$ & - \\
\hline & $\begin{array}{l}\text { Interior, } \\
\text { humid } \\
\text { applications }\end{array}$ & - " - & $\begin{array}{l}\text { Limited moisture content } \\
\text { Minimum visible salt }\end{array}$ & - \\
\hline & $\begin{array}{l}\text { Exterior } \\
\text { applications }\end{array}$ & $-"-$ & $-"$ - & $\begin{array}{l}\text { Maintained fire } \\
\text { performance }\end{array}$ \\
\hline
\end{tabular}

Further details are given in CEN/TS 15912.

The other case is the risk for decreased fire performance due to loss of the fire retardant chemicals by leaching or other mechanisms. This case is mainly for exterior applications, e.g. as façade claddings. Maintained fire performance over time has to be verified.

A European system with Durability of Reaction to Fire performance (DRF) classes has been developed in order to guide the potential users to find suitable FRT wood products [3], see Table 1. The system is based on a North American system [4, 5] and a previous Nordic system [6-8]. It consists of a classification system for the properties over time of FRT wood and suitable test procedures.

The technical specification CEN/TS 15912 is currently being transformed to a full European standard. This paper is an extended version of an earlier paper [9] and includes more products and test data.

The relevant fire class shall be verified according to EN or IMO systems [10, 11]. Maintained fire performance after weather exposure shall be verified according to ISO 5660 [12] or the European system [10].

\section{EXPERIMENTAL STUDY}

\subsection{Hygroscopic properties}

The hygroscopic properties of wood products have been determined according to [7] or the equivalent [3]. The method includes calculation of equilibrium moisture content at two climates, $50 \%$ $\mathrm{RH}$ at $23^{\circ} \mathrm{C}$ and $90 \% \mathrm{RH}$ at $27^{\circ} \mathrm{C}$. The requirement for DRF class INT is moisture content below $30 \%$ in the humid climate. Untreated wood has moisture content below $20 \%$ in that climate. In addition, possible salt crystallisation at the wood surface and exudation of liquid in the wet climate is observed.

\subsection{Accelerated and natural weathering}

For DRF class EXT, the durability of the fire performance at exterior applications has been studied by accelerated ageing according to [8] or the equivalent [3]. Both Method A, i e exposure to 12 one-week cycles of simulated rain and drying and Method B, i e exposure to 6 one-week cycles of which also includes UV radiation have been used. 
$2^{\text {nd }}$ International Seminar for Fire Safety of Facades, Lund (Sweden), 2016

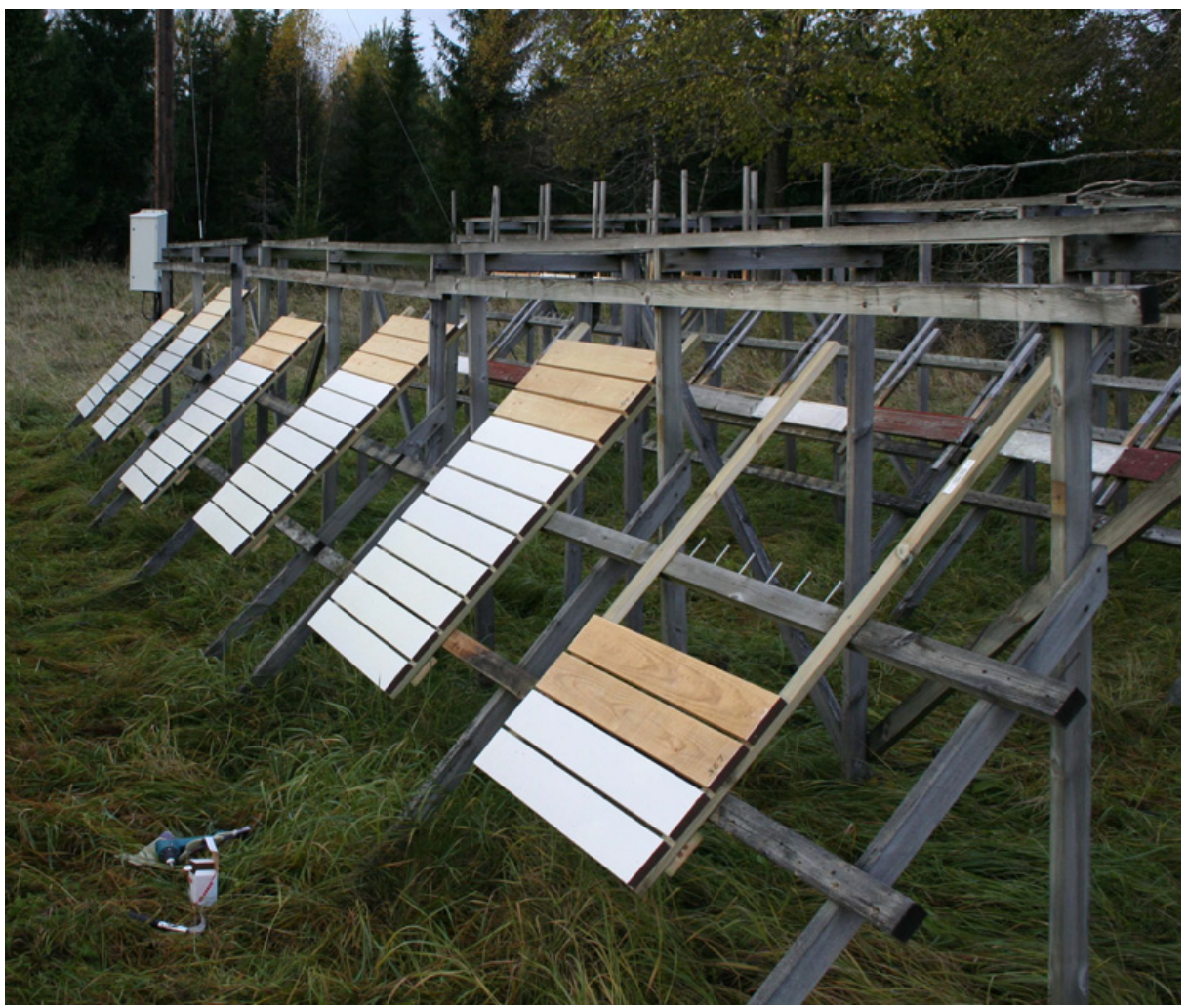

Figure 1. Natural weathering field in Stockholm.

Natural field exposure has been performed with wood panels facing south, both at vertical $\left(90^{\circ}\right)$ and at $45^{\circ}$ slope. In both cases the rear sides of the panels were open. The test field is in the Stockholm area, Sweden, see Figure 1. Results are presented for 1, 2, 3, 5 and 10 years.

\subsection{Fire performance}

The reaction to fire performance has been determined according to ISO 5660 [12] at $50 \mathrm{~kW} / \mathrm{m}^{2}$. Duplicate tests have been run in most cases and the repeatability was very good. The time to flashover in the room corner test has been predicted [13].

\subsection{Mass loss during accelerated and natural weathering}

The weight of the FRT wood panels has been measured after conditioning at $50 \% \mathrm{RH}$ at $23{ }^{\circ} \mathrm{C}$, both initially and after the weathering procedures and is expressed in percentage of the total panel weight.

\section{WOOD PRODUCTS TESTED}

The wood products tested are all wood panelling products, mainly spruce, vacuum pressure impregnated with different fire retardant chemicals. Untreated wood panelling has been used as reference. The initial reaction to fire performance for the FRT wood products has been determined or estimated to 
Table 2. Commercial FRT wood products.

\begin{tabular}{|c|c|c|c|c|c|}
\hline $\begin{array}{l}F R \\
I D\end{array}$ & $\begin{array}{l}\text { Mean FR } \\
\mathrm{kg} / \mathrm{m}^{3}\end{array}$ & $\begin{array}{l}\text { Thick-ness } \\
\mathrm{mm}\end{array}$ & $\begin{array}{l}\text { Width } \\
\mathrm{mm}\end{array}$ & $\begin{array}{l}\text { Approximate initial } \\
\text { density } \mathrm{kg} / \mathrm{m}^{3}\end{array}$ & Type of panel \\
\hline 0 & - & & & & $\begin{array}{l}\text { Tongue and groove } \\
\text { with notched rear side }\end{array}$ \\
\hline $\mathrm{X}$ & $25-60$ & 20 & 135 & 540 & 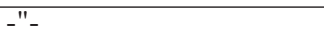 \\
\hline $\mathrm{Y}$ & $45-110$ & 20 & 135 & 510 & -"- \\
\hline $\mathrm{ZA}$ & $95-190$ & 22 & 130 & 690 & Tongue and groove \\
\hline$\overline{Z G}$ & 170 & 22 & 130 & 660 & $\begin{array}{l}\text { Tongue and groove, } \\
\text { factory primed }\end{array}$ \\
\hline $\mathrm{VF}$ & $70-140$ & 20 & 135 & 520 & $\begin{array}{l}\text { Tongue and groove } \\
\text { with notched rear side }\end{array}$ \\
\hline $\mathrm{CI}$ & na & 21 & 145 & 410 & Panel with straight edges \\
\hline $\mathrm{CM}$ & na & 22 & 150 & 470 & 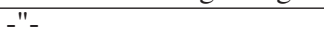 \\
\hline
\end{tabular}

Table 3. Development FRT wood products.

\begin{tabular}{|l|l|l|l|l|l|}
\hline $\begin{array}{l}\text { FR } \\
\text { ID }\end{array}$ & $\begin{array}{l}\text { FR } \mathrm{kg} / \mathrm{m}^{3} \\
-\end{array}$ & $\begin{array}{l}\text { Thickness } \\
\mathrm{mm}\end{array}$ & $\begin{array}{l}\text { Width } \\
\mathrm{mm}\end{array}$ & $\begin{array}{l}\text { Approximate initial } \\
\text { density } \mathrm{kg} / \mathrm{m}^{3}\end{array}$ & Type of panel \\
\hline- & - & 20 & 100 & 540 & Panel with straight edges \\
\hline BS & $107-347$ & 20 & 100 & $640-830$ & $-"-$ \\
\hline FP & $71-228$ & 20 & 100 & $570-670$ & $-"-$ \\
\hline DQ & $89-290$ & 20 & 100 & $570-875$ & $-"-$ \\
\hline BH & $87-236$ & 20 & 100 & $635-790$ & $-"-$ \\
\hline MA & 216 & 20 & 100 & 585 & $-"-$ \\
\hline SI & $84-368$ & 20 & 100 & $625-850$ & $-"-$ \\
\hline FF & $92-169$ & 20 & 100 & $647-657$ & $-"-$ \\
\hline PhF & $413-667$ & 20 & 100 & $826-1007$ & $-"-$ \\
\hline BZ-15 & $78-282$ & 20 & 100 & $470-520$ & $-"-$ \\
\hline BZ-40 & $67-191$ & 20 & 100 & $469-558$ & $-"-$ \\
\hline BZ-30 & $75-229$ & 20 & 100 & $531-544$ & $-"-$ \\
\hline NF & $115-206$ & 20 & 100 & $541-711$ & $-"-$ \\
\hline AF & $120-251$ & 20 & 100 & $560-677$ & $-"-$ \\
\hline DF & $125-556$ & 20 & 100 & $629-1152$ & $-"-$ \\
\hline LG & $114-536$ & 20 & 100 & $614-673$ & $-"-$ \\
\hline NS & $139-619$ & 20 & 100 & $549-680$ & $-"-$ \\
\hline
\end{tabular}

* Three retention levels per FR chemical, the range is given in the table.

be equivalent to class B or at least class $\mathrm{C}$ according to the Euroclass system [10]. Untreated wood is Euroclass D. These data have been used as reference for the fire performance after weathering.

Two main sets of wood products have been studied, one set of commercial FRT wood products X, Y, Z, CI and CM intended for exterior application, a former commercial product VF, and another set of development products [14]. All are wood panels impregnated with fire retardants to different levels of retention, see Tables 2 and 3 .

The size of the specimen for ageing may have some influence on the effects of ageing due to edge effects. $800 \mathrm{~mm}$ long specimen were found to be superior to shorter specimen in a pre-study [15] and have then been used together with edge seals both at accelerated and natural exposure. After the exposures the panels have been cut in a systematic way (with test pieces at the same position from the panels to secure consistency) and used for fire and other tests.

\subsection{Paint systems}

Paint systems are usually needed to maintain the fire performance properties of FRT wood products for exterior applications. Four different paint systems have been used, see Table 4 . The panels for weathering 
$2^{\text {nd }}$ International Seminar for Fire Safety of Facades, Lund (Sweden), 2016

Table 4. Paint systems used.

\begin{tabular}{|l|l|l|l|l|}
\hline $\begin{array}{l}\text { Paint } \\
\text { number }\end{array}$ & Paint type & $\begin{array}{l}\text { Number of } \\
\text { coats }\end{array}$ & $\begin{array}{l}\text { Total amount } \\
\mathrm{g} / \mathrm{m}^{2}\end{array}$ & Comments \\
\hline 1 & Alkyd & $4 *$ & $530-650 * *$ & $\begin{array}{l}\text { 1 coat primer oil, 1 coat alkyd primer, 2 alkyd } \\
\text { top coats (all products solvent borne) }\end{array}$ \\
\hline 3 & Red paint & 1 & 200 & $\begin{array}{l}\text { Swedish red paint (water based) } \\
2 \text { coats with diluted paint, 30 and 15\% resp, } \\
1 \text { top coat of undiluted paint }\end{array}$ \\
\hline 4 & Linseed oil & 3 & $400-550 * *$ & Pigmented oil \\
\hline 6 & Wood oil & 2 & $180-200 * *$ & \\
\hline
\end{tabular}

* Only 2 top coats on factory primed panel, total amount $250 \mathrm{~g} / \mathrm{m}^{2}$;

** The higher amount on panel type Z
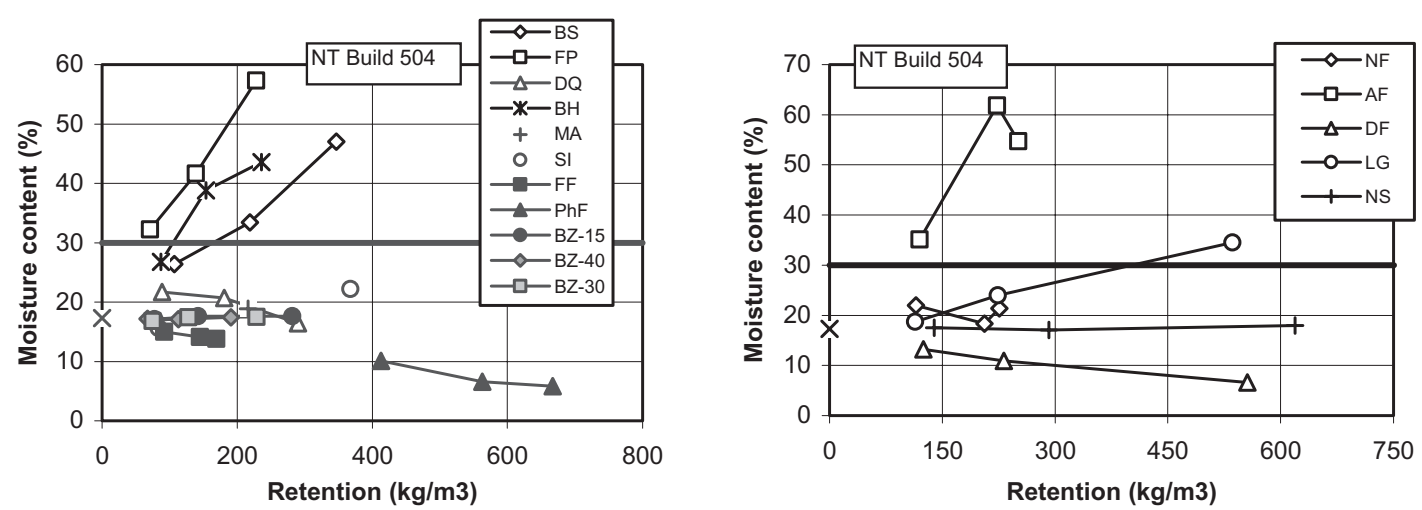

Figure 2. Moisture content at high RH vs retention for FR chemicals and for untreated pine sapwood.

were $800 \mathrm{~mm}$ long and edge sealed, first with an alkyd solvent borne primer and then with a thick coat of a silicone sealer.

\section{HYGROSCOPIC PROPERTIES}

The hygroscopic properties expressed as moisture content at higher relative humidity according to [3] of FR treatments as a function of the retention level are illustrated in Fig. 2. The moisture content is unchanged compared to untreated wood for several FRT wood products.

It is evident from the test data that the moisture content may increase with increased amount of fire retardant chemical added. It is thus important to optimise the FR content not only from an economical point of view, but also to reach the intended fire performance with a safety margin to maintain the fire performance during service life of the product and not jeopardizing the moisture resistance.

\section{COMPARISONS OF REACTION TO FIRE PERFORMANCE}

The reaction to fire performance has been determined in the cone calorimeter ISO 5660 [12] at $50 \mathrm{~kW} / \mathrm{m}^{2}$. All results for the initial reaction to fire performance and after accelerated ageing and natural weathering are summarised and compared in Figs. 3-6. The comparison is based on predicted time to flashover [13]. Several products exhibit high initial reaction to fire performance, but it may be reduced over time during both accelerated and natural weathering.

Comparison of natural weathering exposures at vertical $\left(90^{\circ}\right)$ and at $45^{\circ}$ slope is presented in Fig. 4. No major difference can be observed. 


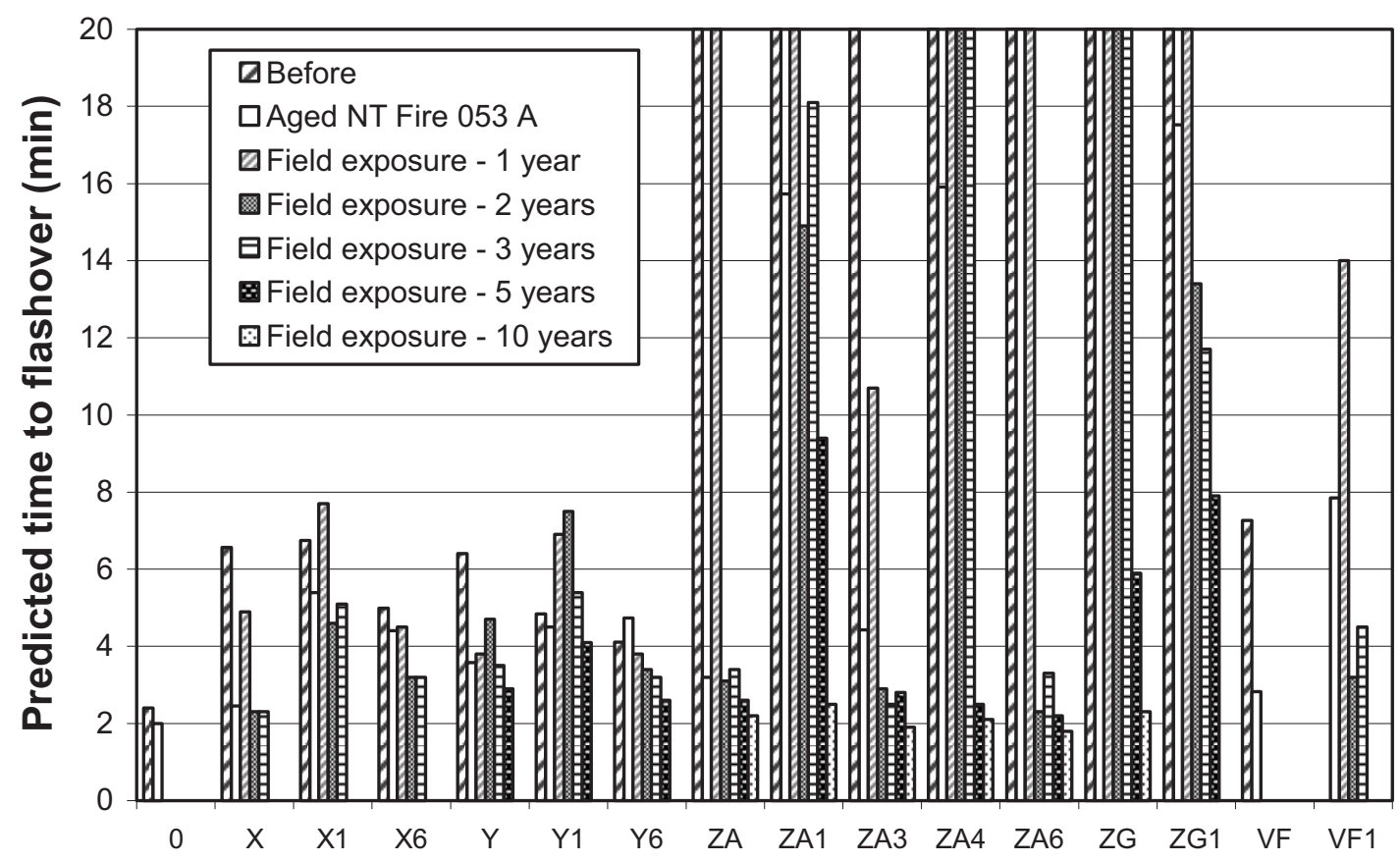

Figure 3. Reaction to fire performance (as predicted time to flashover) before and after accelerated ageing according to NT FIRE 053 Method A, and after natural weathering at $45^{\circ}$ slope during up to 10 years. Untreated spruce $(0)$ and treated (X, Y, ZA, ZG and VF) spruce. Surface coatings with paints number 1, 3, 4 and 6 are included.

Comparison of accelerated weathering exposures according to Method A and Method B is presented in Figs. 5-6. No major difference can be observed.

\section{DURABILITY OF THE REACTION TO FIRE PERFORMANCE}

The reaction to fire performance is reduced both after accelerated ageing and natural field exposure for most of the FRT products. Only a few FRT products maintain a high fire performance after accelerated and natural exposures. The best performance is found at high retention levels and for FRT products with paint as a protective surface coat. Among the paints, the linseed oil paint (number 4) and the factory primed product ZG were found to exhibit a full maintenance of the reaction to fire performance up to three years. The other FRT products were more or less degraded during the weathering exposure, regardless of a protective coat or not. For products with low retention of FR chemicals and low initial fire class, the maintenance of the fire performance could not be evaluated.

The accelerated ageing thus seems to be equivalent to maximum five years of natural field exposure. However, it should be noticed that the field exposure includes also a certain degree of acceleration. The $45^{\circ}$ exposure was intended to include some acceleration, but no major difference to the vertical $\left(90^{\circ}\right)$ orientations was found, see Fig. 4. Some indications of a more severe degradation at the vertical orientation were found in a previous study [9]. This may be explained by the lack of protection on the rear side of the vertical panels, which were open to the weather exposure. On the other hand, the panels at $45^{\circ}$ slope, were at least partly protected on the rear side from direct influence of rainfall and snow. In a real end use, e.g. as a facade cladding, the rear side is totally protected. Such conditions have to be studied further before a more clear guidance on the accelerating factors can be established. 
$2^{\text {nd }}$ International Seminar for Fire Safety of Facades, Lund (Sweden), 2016

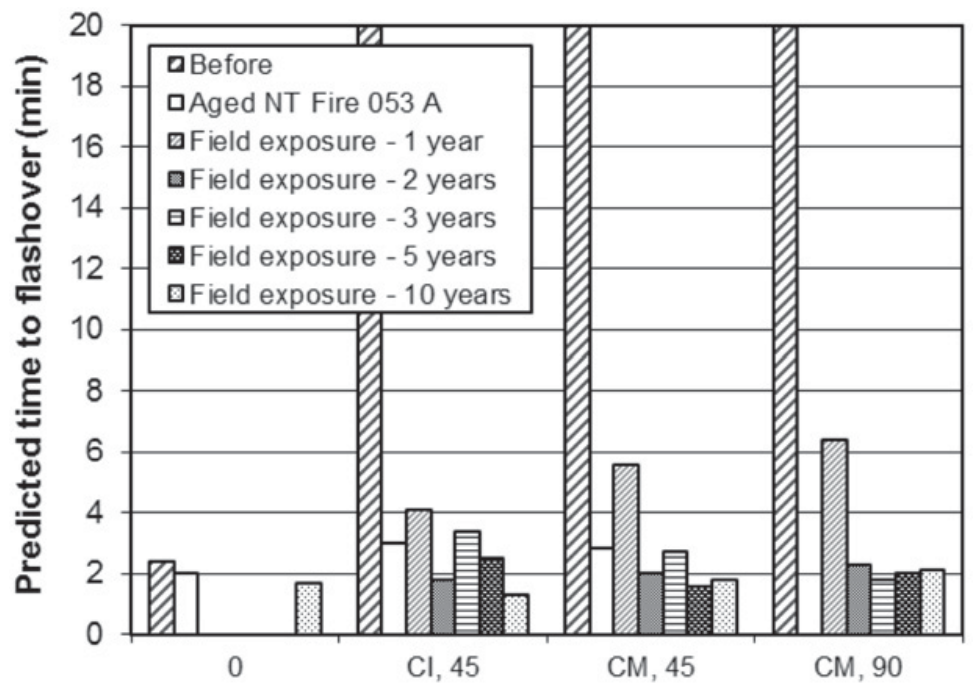

Figure 4. Reaction to fire performance (as predicted time to flashover) before and after accelerated ageing according to NT FIRE 053 Method A, and after natural weathering with wood panels vertical $\left(90^{\circ}\right)$ and at $45^{\circ}$ slope during up to 10 years. Untreated spruce (0) and treated (CI and $\mathrm{CM}$ ) spruce.

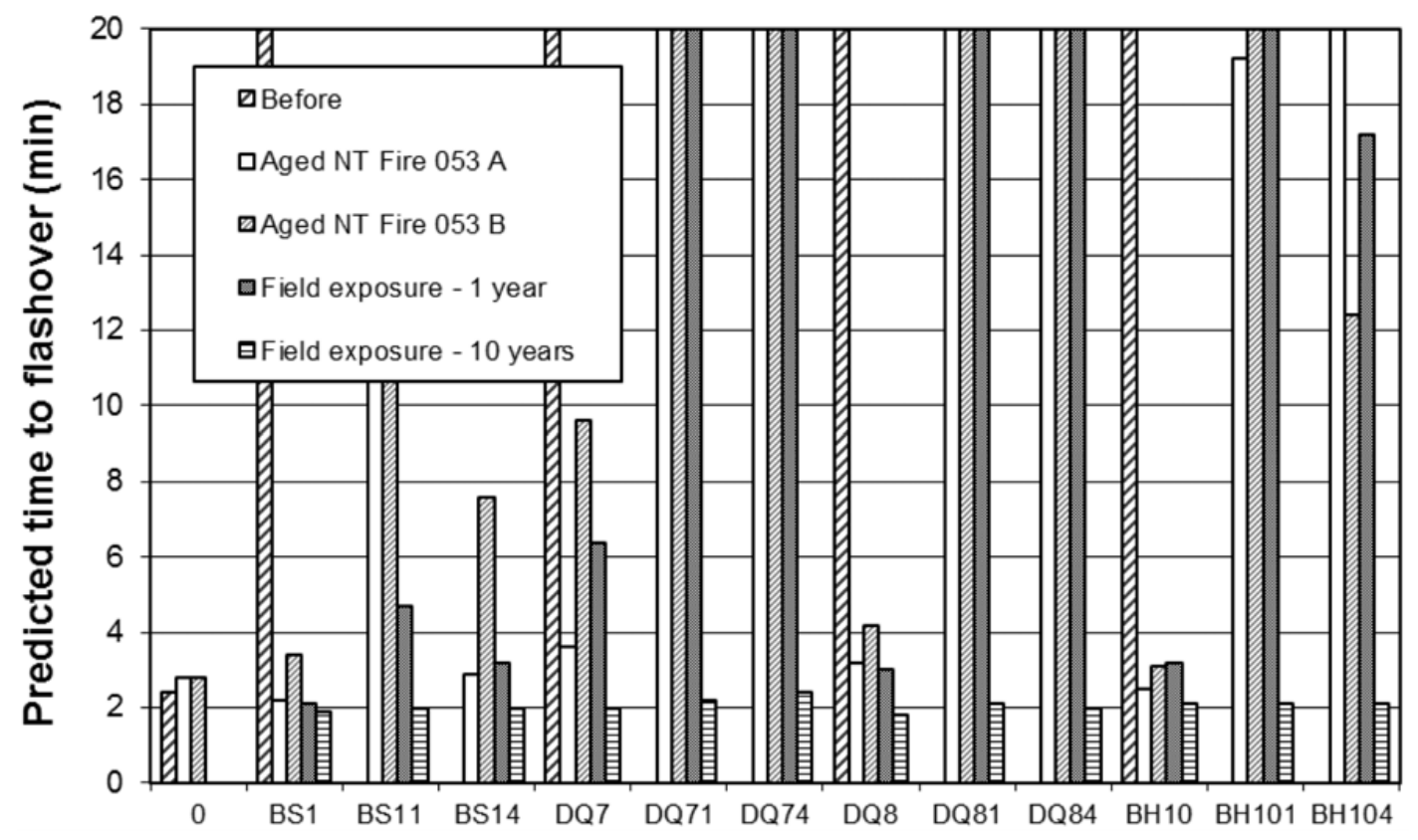

Figure 5. Reaction to fire performance (as predicted time to flashover) before and after accelerated ageing according to NT FIRE 053 Method A and B, and after natural weathering at $45^{\circ}$ slope during up to 10 years. Untreated spruce (0) and FR treated (BS, DQ and BH) spruce. Surface coatings with paints number 1 and 4 are included. 


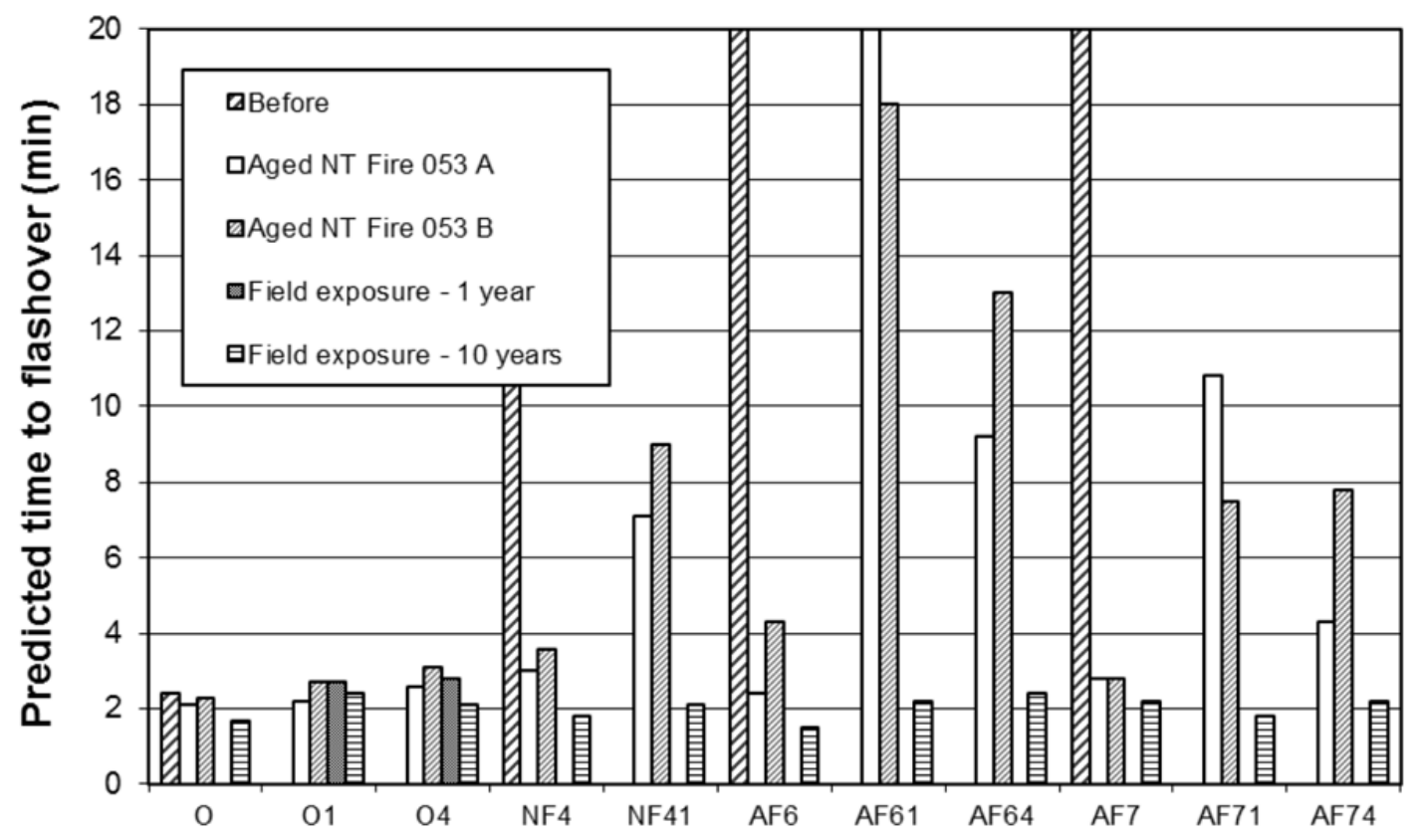

Figure 6. Reaction to fire performance (as predicted time to flashover) before and after accelerated ageing according to NT FIRE 053 Method A and B, and after natural weathering at $45^{\circ}$ slope during up to 10 years. Untreated spruce (0) and FR treated (NF and AF) spruce. Surface coatings with paints number 1 and 4 are included.

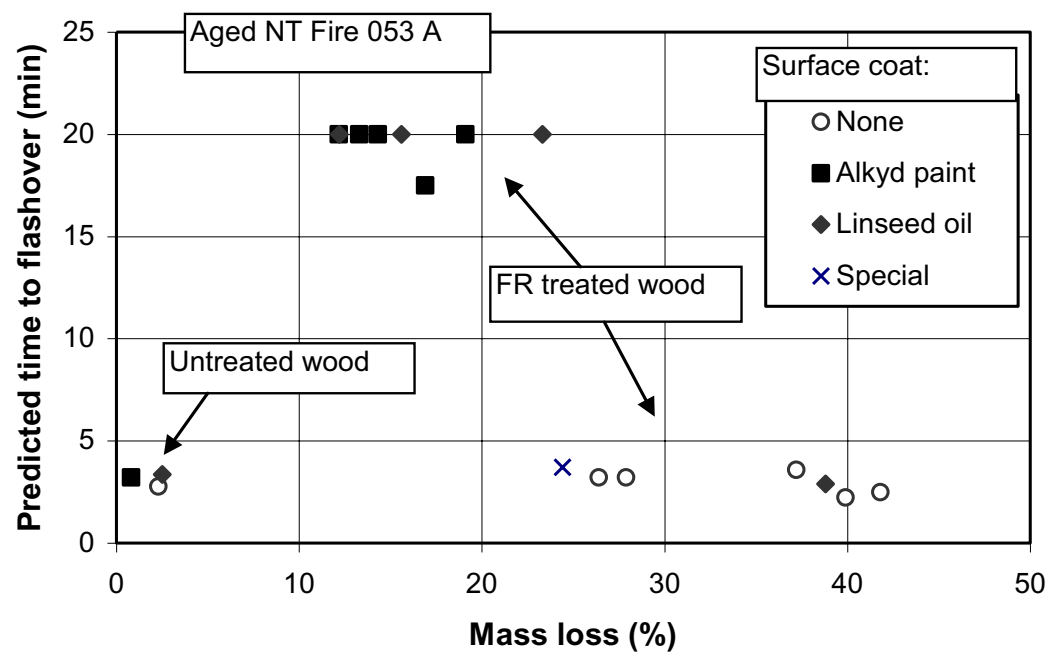

Figure 7. Reaction to fire performance (as predicted time to flashover) vs mass loss during accelerated ageing of FRT and untreated wood according to NT Fire 053 Method A [8].

\section{MASS LOSS DURING WEATHERING}

The mass loss during accelerated ageing and natural weathering may be used as an indicator of the maintained reaction to fire performance over time. Some data are presented in Figs. 7-8. 


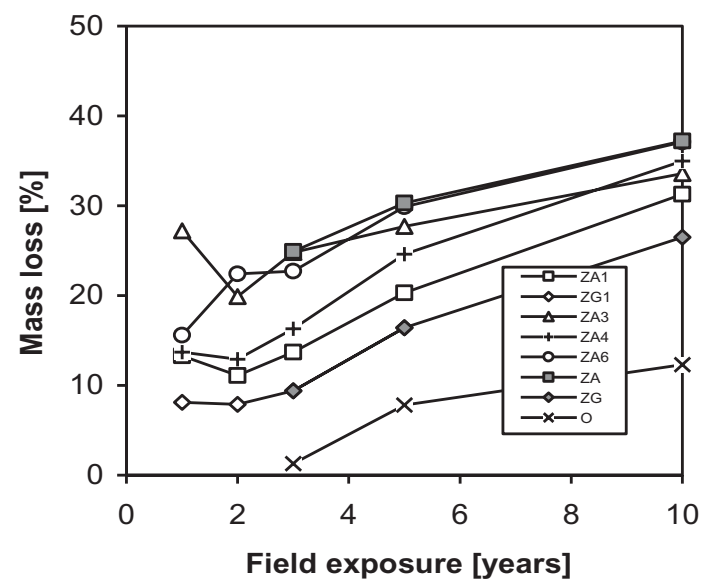

Figure 8. Mass loss during natural weathering of FRT and untreated wood up to ten years.

\section{CONCLUSIONS AND SUGGESTIONS FOR FURTHER WORK}

Main conclusions are:

- A system with Durability of Reaction to Fire performance (DRF) classes to evaluate the fire performance of FRT wood over time at humid and exterior conditions has been developed. It provides a very useful supplement to requirements on the fire performance in national building codes and enables to guide potential users to find suitable and reliable FRT wood products.

- The hygroscopicity of sufficiently durable FRT wood is about the same as for untreated wood, but much higher for simple inorganic salts.

- The fire properties of FRT wood may be maintained after accelerated ageing and natural weathering if the retention levels are high enough, but several FRT wood products loose most of their improved reaction to fire properties during weathering.

- Paint systems contribute considerably to maintain of the fire performance at exterior applications and are usually needed to maintain the fire performance after weathering.

- The mass loss during accelerated aging and natural weathering may be used as an indicator of the maintained reaction to fire performance over time.

- More experience with correlation of natural field testing and accelerated ageing methods is needed.

\section{References}

[1] LeVan S, Holmes C A. Effectiveness of fire-retardant treatments for shingles after 10 years of outdoor weathering. Research Paper FPL 474, 1986.

[2] Östman B, Voss A, Hughes A, Hovde P J, Grexa O. Durability of fire retardant treated wood at humid and exterior conditions. Review of literature. Fire and Materials, 25, 95-104, 2001.

[3] CEN/TS 15912. Durability of reaction to fire performance of fire-retardant treated wood-based products in interior and exterior end-use applications, European Technical Specification, 2012.

[4] ASTM D 2898, Standard Methods for Accelerated weathering of fire-retardant-treated wood for fire testing. American Society for Testing and Materials.

[5] ASTM D 3201, Standard Test Method for Hygroscopic properties of fire-retardant treated wood and wood-based products. American Society for Testing and Materials.

[6] Nordtest method NT FIRE 054. Durability of Reaction to Fire - Performance classes of fireretardant treated wood-based products in interior and exterior end use applications, 2006. 


\section{MATEC Web of Conferences}

[7] Nordtest method NT BUILD 504. Hygroscopic properties of fire-retardant treated wood and wood-based products, 2003.

[8] Nordtest method NT FIRE 053. Accelerated weathering of fire-retardant treated wood for fire testing, 2003.

[9] Östman B, Tsantaridis L. Durability of the reaction to fire performance for FRT wood products in different end use applications - a ten years report, Proc. 12th International Conference on Durability of Building Materials and Components, XII DBMC, Porto, Portugal, 2011.

[10] EN 13501-1. Fire classification of construction products and building elements - Part 1: Classification using test data from reaction to fire tests.

[11] IMO FTP Code (MSC 61/67), International Code for Application of Fire Test Procedures. International Maritime Organization.

[12] ISO 5660-1. Fire tests - Reaction to fire - Part 1: Rate of heat release from building products.

[13] Östman B A-L, Tsantaridis L D. Correlation between cone calorimeter and time to flashover in the room fire test, Fire and Materials, 18, 205-209, 1994.

[14] Östman, Tsantaridis, Mikkola, Hakkarainen, Belloni, Brumer and Piispanen. Innovative ecoefficient high fire performance wood products for demanding applications. Final report for Vinnova-Tekes project InnoFireWood. SP Technical Research Institute of Sweden, SP Report 2006:30, 2006.

[15] Östman B, Tsantarids L, Mikkola E, Hakkarainen T, Nilsen T-N, Evans F, Grexa O. Durability of fire retardant wood - New test methods and round robin. Nordtest project 1527-01. Trätek Swedish Institute for Wood Technology Research, Report P 0211040, 2002. 